\title{
New life expectancy forecasts are too optimistic
}

\author{
Eric Le Bourg
}

Received: 13 September 2021 / Accepted: 17 October 2021 / Published online: 21 October 2021

(C) The Author(s), under exclusive licence to Springer Nature B.V. 2021

\begin{abstract}
Life expectancy at birth (e0) forecasts are used to estimate future pension costs. Previous French official forecasts have often overestimated e0. Recent forecasts published by demographers provide higher $\mathrm{e} 0$ estimates than official forecasts for France, Sweden, Japan and the USA, and do not consider that $\mathrm{e} 0$ could decrease, as in previous years because of flus, heatwaves, or other outbreaks. Too optimistic forecasts make that governments may overestimate future pension needs.
\end{abstract}

Keywords Life expectancy at birth · Forecasts . Pension costs $\cdot$ France $\cdot$ USA $\cdot$ Japan

Forecasting life expectancy at birth (e0) is of importance, particularly because "forecasts are used to estimate future needs and assess policies, e.g., estimate future pension costs" (Vaupel et al. 2021). It is thus of the highest importance to rely on realistic forecasts, in order for policy makers to reach appropriate decisions. These forecasts can be too pessimistic, as it was often the case in past decades (Oeppen and Vaupel 2002), or too optimistic, which

E. Le Bourg $(\bowtie)$

Centre de Recherches sur la Cognition Animale (CRCA), Cenre de Biologie Intégrative (CBI Toulouse), Université de Toulouse, CNRS, UPS, Toulouse, France

e-mail: eric.le-bourg@univ-tlse3.fr implies that future pension needs can be estimated in excess.

The French National Institute of Statistics and Economic Studies (Institut national de la statistique et des études économiques, INSEE) has published forecasts for 2005-2050, 2007-2060, 2013-2070 with different $\mathrm{e} 0$ scenarios (high, central or low), which are used by the French Pensions Advisory Council (Conseil d'orientation des retraites, COR) to estimate pension funding needs. The "central scenario" was the one put forward by the government in its 2020 bill (Article 56, French Government 2020) in a failed attempt to introduce a new pension funding system and was until 2020 the one preferred by the COR (COR 2020, p. 23), its 2021 report being now based on the low scenario (COR 2021, p. 23). Figure 1 shows the three scenarios for each of the INSEE forecasts. Figure 2 shows that privileging the central scenario has often been an error, by illustrating the gap in 2019 between $\mathrm{e} 0$ and the three scenarios (the data for 2020 are still provisional and this year is strongly affected by Covid-19). For men, the 2005-2050 high scenario is more appropriate than the central and low ones, the 2007-2060 central scenario is better than the other ones, and for the 2013-2070 forecast the low scenario is the most appropriate: the central scenario used by the COR first underestimates and then overestimates $\mathrm{e} 0$ in men. For women, the central scenario is appropriate for 2005-2050, but the low scenario is better for the 2007-2060 and 2013-2070 forecasts, 


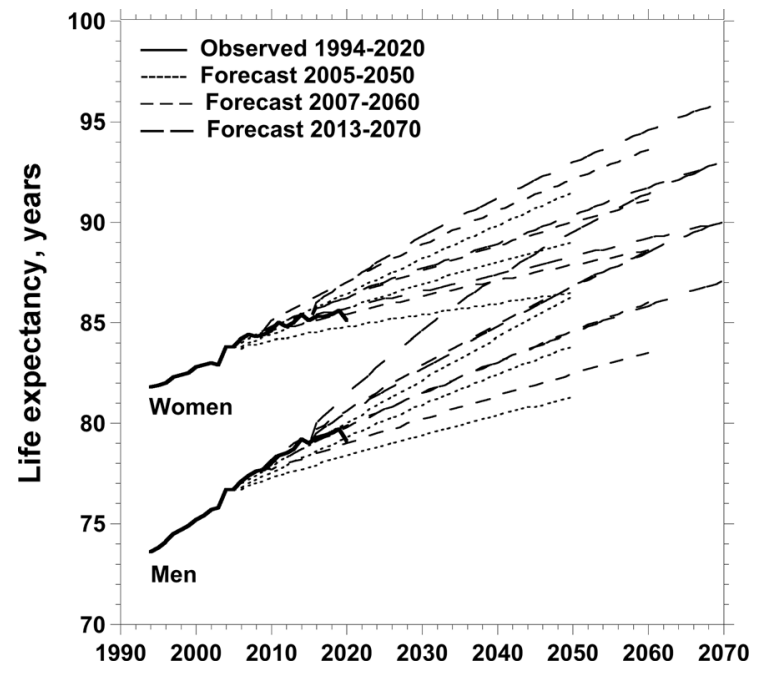

Fig. 1 INSEE forecasts for 2005-2050, 2007-2060, 2013-2070, and observed life expectancy at birth from 1994 to 2020 (provisional for 2020). For each forecast, the low, central and high scenarios show life expectancy at birth

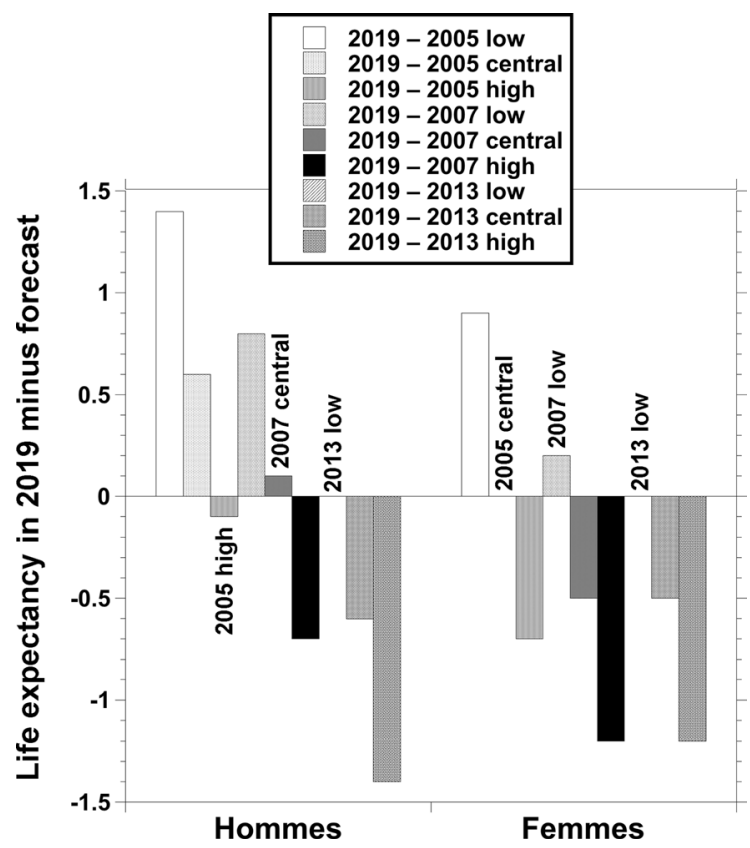

Fig. 2 Differences in 2019 between observed life expectancy at birth and the INSEE scenarios in their low, central and high variants. A positive difference indicates that life expectancy was higher than the forecast and a negative difference that it was lower. The closest scenario to observed results is indicated

and the COR has thus overestimated $\mathrm{e} 0$ of women during many years. In summary, the COR has for a long time relied on the central scenario overestimating $\mathrm{e} 0$ and therefore pension needs. Because these central scenarios have been used by French policy makers to decide, for instance, delaying retirement age in next years and decades, relying on realistic forecasts in the future is crucial. However, too optimistic forecasts are not only the case for France.

Vaupel et al. (2021) have published various scenarios for women's e0 in France, Japan, Sweden, and USA, for the period up to 2050 and 2070. In addition, the authors relied on the updated bestpractice estimate previously used by Oeppen and Vaupel (2002), which adjusts a linear regression to e0 of the record-holding country from 1840 (Norway) to the current years (Japan). This scenario was also updated by removing "problematic country-years" brought to the fore by Vallin and Meslé (2009). However, as indicated below, one may argue that most of these forecasts have a poor chance to provide an appropriate estimate of $\mathrm{e} 0$ in the coming decades.

Firstly, Fig. 2 in Vaupel et al. (2021) shows the best-practice estimate for 1840-2017, and Fig. 1 in Oeppen and Vaupel (2002) shows this estimate for 1840-2000. The main contrast between the two figures is that the current record-holding country, Japan, was very close to the regression line in Oeppen and Vaupel (2002) up to 2000 but, after 2000, it is below the line in Vaupel et al. (2021). In other words, the best-practice regression line now fails to estimate $\mathrm{e} 0$ of the record-country, because record-e 0 increases at a lower speed than previously observed. There is thus no longer a linear rise of record-e0, which casts some doubt that a linear best-practice $\mathrm{e} 0$ rise "close to 100 by 2070 " could be observed, as stated by Vaupel et al. (2021). This is in accordance with the conclusion of Marck et al. (2017) that "predicting a continuous linear growth of life-expectancy in the long term may probably not be relevant if the major progresses have already been accomplished."

Secondly, Fig. 5 in Vaupel et al. (2021) shows the results for France, Japan, Sweden, and USA, of six methods extrapolating e 0 up to 2070 , in addition to the official forecast of these countries: Fig. 3 reports USA results. As emphasised by the authors, there can be a huge variation between these methods (e.g. 8.4 years in USA, from 85.7 to 94.1 years in 2070), which is not an issue if forecasts are biologically plausible. However, forecasting that $\mathrm{e} 0$ could reach 102.8 years in Japan means that most of Japanese women would die in a very few years, as maximal lifespan is close to 


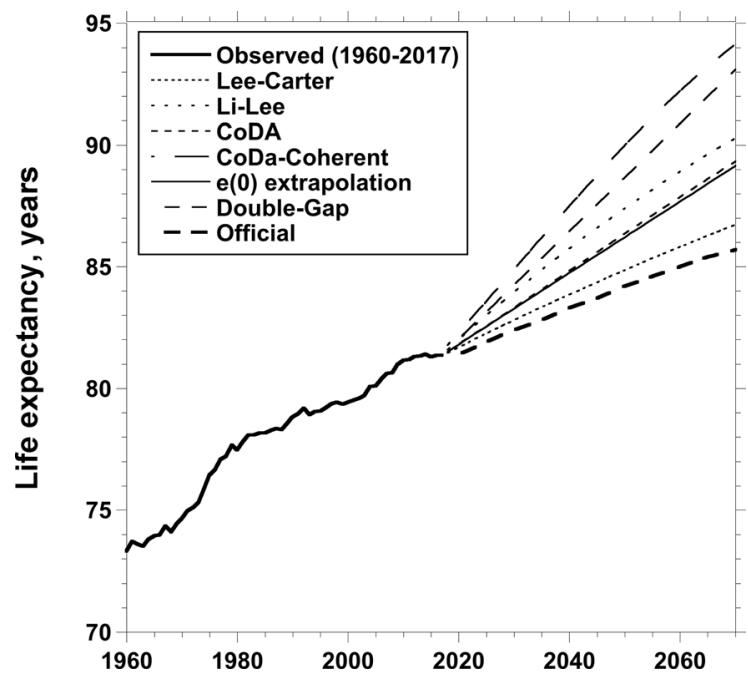

Fig. 3 Female life expectancy at birth in the USA (1960-2017) and forecasts 2018-2070. Reproduced from data of Fig. 5 in Vaupel et al. (2021). The six lines show the various forecasts described by these authors and the official forecast

115 years. This seems hardly possible "because the variability of lifespan would be very low, $50 \%$ of the cohort dying in a very few years, while it is known that there is a high variability of lifespans even in inbred strains and in monozygotic human twins (Finch and Kirkwood 2000; Kirkwood et al. 2005)" (Le Bourg 2012). One could obviously hypothesise that variability could remain the same because maximal lifespan would increase: Vallin and Caselli (1997) showed that if $\mathrm{e} 0$ would be 105 years maximal lifespan would be around 140 years. Such a maximal lifespan is a very strong hypothesis and thus a nearly 105 years $\mathrm{e} 0$ is not very probable, no matter maximal lifespan increases or not. In addition, the stability of US centenarians' death rates since the 1940s, in contrast with the decreasing rates of younger people (Gavrilov et al. 2017), seems to indicate that increasing the lifespan of the last survivors is a challenge. Therefore, it seems that at least some of the forecasts in Vaupel et al. (2021) provide results without any biological ground.

However, another issue with the six 2018-2070 forecasts in Fig. 5 of Vaupel et al. (2021) is that most of them show e 0 increasing suddenly at a higher pace than before 2018. In contrast, the official forecasts keep on the same trend as before 2018. In addition, except for France, all forecasts provide estimates higher than the official forecasts (see the USA results in Fig. 3). To sum up, sudden changes are observed in
2018 simply because forecasts begin in 2018, and not because of any biological or medical breakthrough, and the six forecasts overestimate official ones. These forecasts most probably exaggerate future $\mathrm{e} 0$ and thus could be of no help to estimate future pension costs. In addition, at a time when $\mathrm{e} 0$ is stalling or decreasing from time to time in some countries, because of flu or heatwave in France (Le Bourg 2019), or deaths of despair in the USA (e.g., Case and Deaton 2015), and obviously of the Covid-19 outbreak, taking into account the hypothesis that $\mathrm{e} 0$ could stall or decrease from time to time in coming decades could also be useful (Le Bourg 2021). Forecasting only monotonous $\mathrm{e} 0$ increases is outdated in an epoch that is clearly highly different from the last decades of the last century.

Elaborating e 0 forecasts is not an easy challenge and it seems that, while old forecasts underestimated $\mathrm{e} 0$ increases, as discussed by Oeppen and Vaupel (2002), new forecasts overestimate them. These new forecasts can lead policy makers to erroneous decisions, particularly regarding pension needs, as they can conclude that $\mathrm{e} 0$ will strongly increase in coming decades. Following this conclusion, policy makers could decide, for instance, to delay the retirement age to lower the increasing cost of future pensions, while this cost is overestimated because of these wrong forecasts. It is thus necessary to avoid both traps of e0 under and over-estimations and also to take into account the hypothesis that $\mathrm{e} 0$ could also stall or even decrease in coming years and decades.

\section{References}

Case A, Deaton A (2015) Rising morbidity and mortality in midlife among white non-Hispanic Americans in the 21st century. Proc Nat Acad Sci USA 112:15078-15083

Conseil d'orientation des retraites (2020) Evolutions et perspectives des retraites en France. Rapport annuel du COR Novembre 2020 (Trends and prospects for pensions in France. COR annual report - November 2020)

Conseil d'orientation des retraites (2021) Evolutions et perspectives des retraites en France. Rapport annuel du COR Juin 2020 (Trends and prospects for pensions in France. COR annual report - June 2021)

Finch CE, Kirkwood TBL (2000) Chance, Development, and Aging. Oxford University Press, New York

French Government (2020) Projet de loi organique relatif au système universel de retraite (Draft organic law on the 
universal pension system) https://www.assembleenationale.fr/dyn/15/textes/115b2622_projet-loi\#

Gavrilov LA, Krutko VN, Gavrilova NS (2017) The future of human longevity. Gerontology 63:524-526

Kirkwood TBL, Feder M, Finch CE, Franceschi C, Globerson A, Klingenberg CP, LaMarco K, Omholt S, Westendorp RGJ (2005) What accounts for the wide variation in lifespan of genetically identical organisms reared in a constant environment? Mech Ageing Dev 126:439-443

Le Bourg E (2012) Forecasting continuously increasing life expectancy: what implications? Ageing Res Rev 11:325-328

Le Bourg E (2019) Is life expectancy of French women going to plateau and oscillate? Gerontology 65:288-293

Le Bourg E (2021) Epidemics and forecasts of life expectancy. Gerontology. https://doi.org/10.1159/000517947

Marck A, Antero J, Berthelot G, Saulière G, Jancovici JM, Masson-Delmotte V, Bœuf G, Spedding M, Le Bourg E, Toussaint JF (2017) Are we reaching the limits of Homo sapiens? Front Physiol. https://doi.org/10.3389/fphys. 2017.00812

Oeppen J, Vaupel JW (2002) Broken limits to life expectancy. Science 296:1029-1031

Vallin J, Caselli G (1997) Towards a new horizon in demographic trends: the combined effects of 150 years life expectancy and new fertility models. In: Robine JM, Vaupel JW, Jeune B, Allard M (eds) Longevity to the limits and beyond. Springer, Berlin, pp 29-68

Vallin J, Meslé F (2009) The segmented trend line of highest life expectancies. Pop Dev Rev 35:159-187

Vaupel JW, Villavicencio F, Bergeron-Boucher P (2021) Demographic perspectives on the rise of longevity. Proc Nat Acad Sci USA 118:e2019536118

Publisher's Note Springer Nature remains neutral with regard to jurisdictional claims in published maps and institutional affiliations. 